\title{
MONSANTO, ORGULLO DE PORTUGAL
}

\author{
STANLEY BRANDES ${ }^{1}$ \\ University of California
}

Resumen: El artículo investiga el concurso que tuvo lugar en 1938 durante el régimen fascista de António de Salazar con el fin de seleccionar «el pueblo más portugués de Portugal». En torno a este evento tuvo lugar una cercana colaboración entre etnólogos profesionales y el gobierno de derechas del momento. Este artículo ofrece una interpretación del mencionado concurso en el contexto de unas relaciones internacionales turbulentas, particularmente como reacción a la amenaza de una posible invasión española. Finalmente, fue más la prolongada y muy celebrada búsqueda del pueblo más portugués de Portugal, y no tanto la selección de un pueblo triunfante en particular, lo que capacitó al gobierno para defender sus demandas territoriales y afirmar sus metas nacionalistas.

Palabras clave: Portugal, historia de la península ibérica, António de Salazar, Monsanto, nacionalismo, antropología, fascismo.

Aвstract: This article concerns a contest, initiated in 1938 under the fascist regime of António de Salazar, to select «the most Portuguese village in Portugal.» It demonstrates the close collaboration between professional ethnologists and the right wing government of the day. The article interprets the contest in the context of turbulent international relations, particularly as a reaction to the threat of a Spanish invasion. In the end, it was the lengthy, much-celebrated search for the most Portuguese village in Portugal, rather than the selection of a single triumphant village, that enabled the government to defend its territorial claims and assert its nationalistic goals.

KeYwords: Portugal, Iberian history, António de Salazar, Monsanto, nationalism, anthropology, fascism.

En el contexto europeo, las ciencias sociales siempre han reflejado las situaciones y cambios políticos del momento. La conexión entre la ideología del gobierno y la academia fue particularmente destacada en la mitad del siglo XX

\footnotetext{
1 brandes@berkeley.edu
} 
en España, Portugal, Italia y Alemania. De hecho, en el caso de la Península Ibérica, fue en ese período cuando la antropología social experimentó su pleno nacimiento y florescencia (Brandes, 2011). Esta circunstancia contrasta fuertemente con el desarrollo de la academia en el Cono Sur de Latinoamérica a lo largo de las décadas de los años sesenta y setenta, en donde los regímenes autoritarios suprimieron prácticamente el campo de la antropología social. El objetivo de este trabajo es explorar un episodio poco conocido en la historia de Portugal que muestra en parte por qué las ciencias etnológicas tuvieron una recepción tan positiva durante el gobierno del dictador António de Oliveira Salazar, desde 1932 hasta 1974 (Ibid.). Este caso sirve para ilustrar la cercana conexión entre los empeños antropológicos y los regímenes fascistas que prevalecieron en la Península Ibérica durante casi cuatro décadas.

Nuestro principal interés se enfoca en un peculiar concurso organizado durante 1938 para identificar primero y glorificar más adelante " $A$ aldeia mais portuguesa de Portugal» —el pueblo más portugués de Portugal—. Pero antes de entrar en detalles sobre el concurso, debemos tomar en consideración el contexto político en el que este enigmático episodio tuvo lugar. En 1938, Europa Occidental se encontraba a sí misma en una extenuante agitación política, repleta de invasiones, migraciones forzosas y actos de violencia colectivos. Ése fue el año del Anschluss, cuando las tropas alemanas ocuparon y anexionaron Austria. El mismo año fue testigo de un extensivo pogromo conocido como Kristallnacht, que supuso el saqueo e incendio en masa de los centros de negocio y casas de culto judías. España, en medio de la agonía de la sangrienta guerra civil, veía cómo la corriente se movía a favor del bando nacional de Franco. Las batallas decisivas de Teruel, Alicante, Barcelona y a lo largo de la cuenca del Ebro prefiguraban en esos momentos casi con certeza la victoria de Franco. En Italia, el Manifiesto de la Raza presentado por Mussolini, declaraba que todos los italianos eran descendientes de los arios y prohibía a las supuestas razas inferiores contraer matrimonio con italianos y trabajar en profesiones liberales.

Mientras tanto, la pequeña Portugal — que en esos tiempos contaba con una población de menos de ocho millones de habitantes y con una superficie de 92.000 kilómetros cuadrados, el tamaño aproximado del estado estadounidense de Indiana-, trataba de mantener la neutralidad en medio de las presiones internacionales. En 1938, el país se enfrentó con un repentino flujo de refugiados judíos — recientemente forzados a huir desde los países del norte-, así como por la amenaza de una invasión española. Agobiado por la presencia de un pequeño y débil ejército (Payne, 2008: 96), en esos momentos Portugal era, 
junto con Grecia, el país más vulnerable de Europa. Facciones radicales del partido fascista de la Falange española, alentadas por la toma alemana de Austria y la anexión del área de los Sudetes en Checoslovaquia, abogaron por la invasión de su vecino del oeste, con el fin de crear una unificada Gran Espańa, que incluiría el territorio portugués. De hecho, Franco ordenó preparar a su Estado Mayor Supremo un Estudio para el Plan de Campaña N. ${ }^{\circ} 1$, un documento en el que se refería a Portugal como «el enemigo» y se calificaba cualquier futura invasión de ese país como la última de una larga lista de ataques españoles y franceses en Portugal (Ibid.). Entre otros eventos que alarmaron seriamente a las autoridades portuguesas, el influyente cuñado y cercano consejero político de Franco, Ramón Serrano Suñer, anunció que, geográficamente hablando, Portugal realmente no tenía derecho a existir (Payne, 2008: 82-83). Si bien la planificada invasión española de Portugal nunca llegó a producirse, este período muestra la obsesión de la Europa fascista por reforzar, expandir y redefinir las fronteras del estado. Fue también un período caracterizado por un extremado sentimiento nacionalista, manifestado en buena parte mediante debates populares y proclamaciones oficiales concernientes a la identidad racial y cultural.

Es dentro de este amplio contexto en el que debemos comprender la verdadera peculiaridad de los proyectos políticos de 1938: un concurso oficial patrocinado por el gobierno con el fin de identificar $A$ aldeia mais portuguesa de Portugal —El pueblo más portugués de Portugal—. Este concurso fue ideado y promovido por António Ferro, periodista, ardiente partidario del Estado Novo de Salazar, admirador entusiasta de Mussolini, y director del Secretariado de Propaganda Nacional desde su fundación en 1933 hasta que se convirtió en la Secretaría Nacional de Información en 1947. Las directrices oficiales establecieron que el premio sería para el pueblo que demostrase «la mayor resistencia ejercida hacia las transformaciones e influencias extranjeras y en un estado de conservación del mayor grado de pureza en los siguientes aspectos: (1) residencia; (2) muebles y bienes del hogar; (3) ropa; (4) artes populares e industrias; (5) actividad comercial; (6) medios de transporte (por tierra, mar, o río); (7) poesía, historias, supersticiones, juegos, canciones, música, coreografía, teatro, festivales y otras prácticas; y (8) características de la topografía y del paisaje» (citado en Pais de Brito 1982: 511-512). Para ser elegibles, se requería que las comunidades contasen también con un grupo coral. De este modo, aquellas comunidades que no tenían coros eran inmediatamente descalificadas.

Desde el 7 de febrero de 1938, cuando el concurso fue anunciado y las reglas para competir se hicieron públicas, hasta el 12 de octubre del mismo año, cuando 
los resultados finales fueron anunciados, todo Portugal parecía estar centrado en el proceso del concurso. Diário de Notícias, el periódico de Portugal más importante de la época, publicó artículos de forma regular dirigidos a despertar el suspense y el interés popular sobre este concurso. De ahí la aparición de un extenso y detallado artículo sobre la provincia sureña del Algarve, que comienza con la destacada escritura en cursiva: La aldea más portuguesa de Portugal. Debajo de este encabezamiento, en letra más pequeña y sofisticada, aparece el nombre del pueblo candidato: Odesseixe — lindo nome e linda terra-Odesseixe — bello nombre y bella tierra. La mitad de la página está ocupada por una fotografía de una calle escalonada con la leyenda "Uma rua da formosa povacão de Odesseixe» -Una calle de la espléndida comunidad de Odesseixe-. El comienzo de un largo artículo acerca de este pueblo ocupa el resto de la página.

Podemos tomar también en consideración otra página completa escrita el 4 de Septiembre de 1938 en el Diário de Noticias, en la cual se anunció que uno de los juris — esto es, la comisión de selección — estudiaría el Baixo Alentejo como pueblo apropiado para ser candidato al concurso. En la parte superior de la página aparece escrito en grandes letras cursivas La aldea más portuguesa de Portugal, a lo que sigue el planteamiento de la cuestión en destacada escritura de imprenta: «Será Peroguarda ou a Salvada, representantes do Baixo Alentejo?» — ¿Serán Peroguarda o Salvada representantes del Baixo Alentejo?-. Una fotografía amplia de un patio con casas encaladas ocupa la mayor parte del resto de la página. En la parte inferior de ésta y continuando en una segunda página nos encontramos con el comienzo de un extenso artículo en el que se describe la maravillosa belleza de estas dos comunidades. Un mes más tarde, el 22 de Septiembre, otro artículo con formato similar anticipa la posible candidatura de Vila Chã, en la norteña provincia de Minho. El subtítulo del artículo afirma con audacia, «Vila Chã, en Minho ofrece al juri del concurso un espectáculo deslumbrante, digno de gran consideración». Con el uso constante de este tipo de lenguaje laudatorio, los periódicos portugueses y otras publicaciones populares registraron las visitas de los juri y sus evaluaciones desde un extremo al otro del país. El Diário de Notícias y otros medios de comunicación de amplia difusión en Portugal mantuvieron el interés público durante la mayor parte del año acerca de los procedimientos del concurso que estaban llevándose a cabo. ¿Y cuál iba a ser el premio que iba a ganar el pueblo victorioso? La comunidad ganadora sería presentada con el codiciado "Galo de Prata» —el gallo de plata—, la escultura en plata de un gallo con un tamaño que podía cogerse en brazos, conveniente para su exhibición pública. La selección de un gallo puede ser explicada por el hecho de que el gallo ha simbolizado a la nación portuguesa durante largo tiem- 
po, del mismo modo que el toro ha representado a Castilla, el burro a Cataluña y la vaca a Galicia (Brandes, 2011:45). Con el fin de seleccionar al ganador del concurso, las Juntas provinciales nombraron juris locales, constituidos cada uno de ellos por cinco miembros: un etnógrafo, un musicólogo, un director de museo regional, un representante de la Oficina Municipal de Turismo local, además del presidente de la Junta Provincial, que podía votar en caso de producirse un empate. Cada juri local fue encargado de elegir dos pueblos candidatos dentro de su área de jurisdicción, correspondiendo aproximadamente cada área a una de las provincias peninsulares. (Inexplicablemente, las islas portuguesas de Madeira y Azores fueron excluidas del concurso). Para llevar a cabo la selección entre los veintidós pueblos finalistas, el Secretariado de Propaganda Nacional nombró a un juri nacional compuesto por tres etnógrafos, un musicólogo, dos representantes «prestigiosos» de las artes y las letras, así como el director de la propia Secretaría (Pais de Brito, 1982: 512). Como es evidente, los etnógrafos y folkloristas ejercieron una influencia significativa en lo que respecta a la selección final.

El objetivo general del concurso, de acuerdo con la interpretación de Vera Marques Alves, era «fortalecer la imagen política de la eficacia del régimen [de Salazar] dentro y fuera de las fronteras del país» (Alves, 1997: 237). Sin embargo, a diferencia de otros proyectos patrocinados por el Secretariado de Propaganda Nacional, no estaríamos exagerando al calificar el Galo de Prata como una extraña competición. Cuando menos, las reglas del concurso plantearon numerosas cuestiones taxonómicas. Comenzando con la simple consideración: ¿Cómo puede una comisión seleccionar la aldeia o pueblo más portugués en Portugal? Para empezar, el término aldeia, en el discurso oficial del gobierno portugués, denota una administración y un estatus territorial particular, una población de un tamaño determinado y un carácter social específico. En el lenguaje ordinario, el término puede aplicarse a un rango amplio de comunidades, con independencia de su denominación formal. De hecho, más de una década antes del concurso, en 1927, la comunidad ganadora había sido elevada oficialmente del estatus de aldeia a la categoría más prestigiosa de villa, un título que al parecer no suponía ningún impedimento para su victoria, ya que la comunidad parecía permanecer dentro de los límites de la definición popular de aldeia.

Cabe también preguntarnos cómo es posible que una comunidad particular en Portugal, o en otro lugar, pueda ser presentada como la nación entera. En un inteligente estudio sobre la relación entre los etnógrafos locales y el Secretariado de Propaganda Nacional, Vera Marques Alves hace énfasis en el criterio estético utilizado tanto por los juries en el Galo de Prata, como también por los 
responsables de las celebraciones y exhibiciones que tuvieron lugar después del concurso. La investigadora denomina este proceso «estetización como medio de la representación de la cultura popular» (Alves, 1997: 238). Para mantenerse al margen de cualquier duda, los informes de las deliberaciones juri otorgan especial relevancia a las características arquitectónicas, los trajes regionales, las actuaciones de canto y danza folklóricas, la belleza del entorno paisajístico, así como la situación de cada comunidad dentro de éste, todo lo cual suponía demostrar de modo ideal la abundancia de rasgos portugueses no adulterados y la ausencia de influencia extranjera. De este modo, constituye un caso típico la selección de rasgos que se hace para describir al pueblo Torre de Bera en el siguiente artículo de prensa (Díario de Notícias 20 September 1938):

Torre de Bera, vecino de Coimbra, la hermosa Coimbra, está construido en las laderas de las colinas que serpentean por toda esta región y la dotan de espiritualidad. Encontramos en esas partes un aire de remembranza ascética, que inclina a la meditación, y por tanto a la poesía. Torre de Bera, tierra de hermoso nombre, es tan armoniosa y dulce como un rosario de versos. Es una tierra musical. La música vive en las almas de sus habitantes, constantemente llenos de... la melodía de las voces de mujeres cantando.

Un ejemplo similar, considerando parte de la descripción del pueblo de Paul, aparece introducido con el titular de prensa «Un encantador día en Paul» (Diário de Noticias 28 de septiembre de 1938):

(De nuestro enviado especial) - A lo largo de la noche anterior - tuvo lugar la melancólica «Procesión de los Penitentes» en el pueblo de Paul. Era como el más puro de los amaneceres, la mañana más radiante que cubrió los días de nuestro viaje a lo largo y ancho de Portugal. Al abrir los ojos, en el dulce sueño que las sábanas frescas nos dieron, en la casa del hospitalario Padre Antonio Cruz, sacerdote de la parroquia, todos los alrededores eran de color rosado. En esos momentos Paul parecía un pueblo sacado de un cuento de hadas. Todo parecía encantado.

Alves (1997) destaca con precisión la importancia que la belleza, la nostalgia, el primitivismo y el ambiente bucólico jugaron en la selección de los pueblos. Fue un concurso, afirma esta autora, que evoca imágenes de la pobreza estética (Ibíd.: 254) —un concurso en el que personas urbanas y con sofisticados estudios superiores hicieron sus selecciones basándose en imágenes idealizadas del campo. Pero, con independencia de los criterios utilizados, no es posible imaginar, dada 
la variedad regional de Portugal, que un único pueblo pudiera llegar a representar a toda la nación.

¿Qué podemos decir acerca de la responsabilidad de los juris para hacer la selección conforme a la ausencia de componentes extranjeros? ¿Son elementos extranjeros las tejas y los patios interiores, ambos traídos a la Península Ibérica por los árabes? ¿Acaso el cristianismo, impuesto por las tribus germánicas tras la caída de Roma, da evidencia de la influencia externa? Al examinar los criterios del concurso, nos encontramos obviamente con un resurgimiento del romanticismo de principios del Siglo XIX, que fue en sí mismo de origen germánico (Galinier, 2006). Por tanto, ¿fueron los criterios empleados por las comisiones de selección una evidencia de la influencia extranjera?

Yendo todavía más lejos, ¿la misma palabra aldeia, derivada del árabe, muestra por sí misma evidencia de la influencia extranjera, una influencia que implícitamente socavaría toda la búsqueda de «a aldeia mais portuguesa de Portugal»? Como agentes involuntarios de la filosofía nacionalista de Johann Herder (Galinier, 2006; Zammito, 2002), los miembros de la comisión recorrieron el campo con el fin de encontrar la expresión más pura del carácter nacional de Portugal, aquel pueblo que expresase la forma más antigua de ser Portugués. En efecto, fueron en busca de un museo vivo, de una historia fosilizada. Este objetivo habría sido imposible de alcanzar por comisión alguna. Es interesante hacer notar que el lenguaje — una fuente primaria de evidencia para los historiadores de la cultura - no entró a formar parte de las directrices oficiales o de las deliberaciones de la comisión. Si lo hubiera hecho, este rasgo habría descalificado del concurso a cualquier comunidad portuguesa, por el hecho de hablar todas ellas una lengua originada con los romanos. A pesar de estas derivaciones fundamentales de las bases del concurso, la búsqueda logró finalmente identificar a través de las comisiones de selección a veintidós comunidades cualificadas para concursar.

Después de haber sido espléndidamente agasajado por todos los pueblos finalistas, el juri nacional seleccionó a Monsanto de Beira Baixa como ganador. Tras la presentación formal del Galo de Prata, António Ferro, director del Secretariado Nacional de Propaganda, declaró: «Este concurso tiene valor, sobre todo, por la oportunidad que nos ofrece para profundizar en la tierra portuguesa, para descubrir algunos de sus secretos, para encontrar aquí y allá, escondido entre las rocas, en la altura de las montañas, o en el corazón de los valles, el lugar de nacimiento de una raza». Y continúa clamando, «ipueblo portugués, sigamos el 
ejemplo de Monsanto, el pueblo más portugués de Portugal! Cualesquiera que sean las vicisitudes a las que nos tengamos que enfrentar, confiemos en nosotros mismos y en los líderes de nuestra regeneración moral; hagámonos saber cómo esperar con prudencia, para subir a la parte superior de la fortificación, en el momento más oportuno, a los buques de la abundancia... ¡Las personas más ricas... no son los que poseen la mayor cantidad de dinero, sino las que tienen más alma!» (citado en Nascimento, 2011: 2). En declaraciones públicas como la anterior, las metáforas referidas al paisaje natural y al cuerpo humano, así como al alma o al espíritu, subrayan el romanticismo predominante a lo largo de este concurso.

Prácticamente todas las descripciones publicadas de Monsanto se refieren a su configuración fuera de lo común, con algunas casas prendidas y otras integradas a rocas gigantes de granito, con calles empedradas que suben por una empinada ladera desde el valle. La periodista Marta Cardoso formuló así su famosa pregunta:

Nunca se sabe em Monsanto se a casa nasce da rocha se a rocha nasce da casa.
Nunca se sabe en Monsanto si la casa nace de la roca si la roca nace de la casa.

Y la selección de Monsanto como el pueblo más portugués de Portugal ha convertido a esta declaración en un dicho popular, que se reproduce en casi todo lo que se ha escrito sobre esa pequeña comunidad.

En realidad, Monsanto se compone de dos freguesias o parroquias: Sáo Miguel, dramáticamente montańoso, escarpado y rocoso, y coronado por las ruinas de un castillo medieval; y Sáo Salvador, una comunidad de aspecto bastante corriente, situada en el fondo del valle, y que no contiene ni arcaicas ni tampoco sorprendentes características arquitectónicas o topográficas. A pesar de que la población de São Salvador es mucho mayor, es São Miguel el que recibe la atención casi exclusiva en las descripciones y análisis del concurso del Galo de Prata. Joaquim Pais de Brito, parafraseando las noticias en O Diario da Manhã y citando el lenguaje idéntico del periódico, informa que Monsanto se convirtió en ganador debido al "perfil arcaico de sus casas, calles, mobiliario y edificios públicos... [además de] la existencia de casas patricias, monumentos que muestran la evidencia de su pasado glorioso, y un castillo a menudo atacado por el enemigo y siempre defendido heroicamente, a lo que se añade una fe católica fuertemente arraigada» (Pais de Brito, 1982: 122). Fue sin duda la parroquia de São Miguel, más que el municipio de Monsanto en su conjun- 
to, lo que fundamentalmente capturó la atención de las comisiones locales y nacionales del concurso.

Dos antropólogos han analizado la victoria de Monsanto. El primero de ellos, Joaquim Pais de Brito (1982) muestra cómo los criterios de los juri, tal como fueron informados en la prensa portuguesa, se hicieron eco de los valores y los objetivos del régimen de Salazar. Pais de Brito resume las noticias de la victoria de Monsanto en $O$ Diario da Manhã utilizando el mismo lenguaje que el informe del periódico: «... trajes tradicionales, la pureza del pavimento de la calle, aceras, algunos de los peinados de las jóvenes, la belleza de los monumentos, las habilidades de los trabajadores, la tradición católica (este año apenas 6 de los 2.000 habitantes no cumplieron con las donaciones obligatorias a la iglesia [o preceito da desobriga]), la hermosura del paisaje, la historia claramente marcada en el granito y en las almas de la gente, la abierta hospitalidad, dio a Monsanto una posición abrumadora entre el resto de los competidores» (Pais de Brito, 1982: 13).

Los informes de prensa, como muestra Pais de Brito, se complementan perfectamente con la imagen que António Ferro dio en 1939 del temperamento y carácter Monsantino: «la imagen de nuestra honorable y limpia pobreza, que no envidia las riquezas de nadie.... [Las] personas viven felices, rezando, cantando y bailando, proyectando optimismo a las ciudades cansadas, comprendiendo, como pocos lo hacen, el resurgimiento portugués, más codicioso por el bienestar espiritual — la escuela, la iglesia, la familia — que por los bienes materiales» (citado por Alves, 1997: 250).

Una segunda interpretación, publicada en 1997 por la antropóloga Vera Marques Alves, hace énfasis en las conexiones y los procesos políticos que tuvieron lugar en la victoria de Monsanto. Alves señala que, por ejemplo, Monsanto se había ganado una larga reputación entre la élite de la Beira Baixa, por hacer gala de una profundidad histórica única y extraordinaria, dotada de ricas tradiciones culturales, de un folklore no adulterado y de un entorno visualmente sorprendente. Alves muestra cómo a lo largo de todo el concurso los gustos de la élite orientaron la selección de los pueblos candidatos y de también de Monsanto, la comunidad ganadora. De hecho, los pueblos adaptaron su presentación formal a lo que consideraron que podría impresionar a los ricos e influyentes habitantes de las ciudades. Algunos políticos poderosos procedentes de la ciudad y capital Castelo Branco, con cercano y ficticio parentesco y lazos políticos con miembros del Secretariado de Propaganda Nacional, promocionaron intensamente a 
su pueblo favorito. La presión que ejercieron sobre el juri nacional finalmente prevaleció.

¿Qué opiniones expresan hoy en día los miembros de la élite urbana intelectual sobre Monsanto? De modo manifiesto los colegas antropólogos juzgan en todo caso el concurso de 1938 como un evento de curiosidad pintoresca y cierta locura. Al mismo tiempo, casi todos con los que he hablado alaban la belleza de Monsanto y su impresionante localización. En mi experiencia, los encuestados no diferencian entre las parroquias de São Miguel y São Salvador, si bien sus evaluaciones posiblemente no incluyen la bastante corriente parroquia de São Salvador. También es cierto que, como algunos colegas señalan, el «pueblo más portugués de Portugal» se distingue de cualquier otro pueblo portugués. Es excepcional, más que representantivo de Portugal. Y esa circunstancia, igualmente válida tanto en 1938 como en la actualidad, probablemente actuó en su favor. Imaginemos que las comisiones hubieran seleccionado como el más portugués a uno de los pueblos notoriamente encalados en el Algarve — podemos nombrar a candidatos reales como Alte o Odeceixe- Estas comunidades, como ocurre con la mayoría de los pueblos y ciudades rurales a lo largo de todo el Portugal peninsular, son inmediatamente reconocidos como típicos de su región. Sin embargo, no sucede lo mismo con el sui generis Monsanto - o por lo menos con la famosa parroquia de São Miguel, a la que pocos serían capaces de identificar como emblemática de una provincia particular-.

Los investigadores portugueses suelen mencionar el extraño hecho de que el pueblo más portugués de Portugal esté ubicado cerca de la frontera con España. Pero si bien Monsanto se encuentra bastante próximo a la frontera - treinta kilómetros para ser exactos—, no está realmente localizado en la frontera. Son tal vez las ruinas antiguas de un castillo, al que se atribuye haber servido de defensa contra la invasión española, lo que para la percepción portuguesa representa a Monsanto como una comunidad fronteriza. De hecho, la imagen de Monsanto como un defensor del territorio portugués probablemente haya contribuido a su éxito. Recordemos que el concurso del Galo de Prata tuvo lugar en un momento histórico en el que Portugal se sintió amenazada por la posibilidad de una invasión y anexión por parte de las fuerzas de Franco. Un asentamiento portugués que había jugado un papel histórico en la defensa del territorio de Portugal, y que ahora era declarado formalmente como extraordinariamente portugués, no habría podido servir como elemento disuasorio contra los objetivos expansionistas españoles. Pero sí que al menos puede haber actuado como afirmación simbólica de la integridad de las fronteras nacionales portuguesas. 
De hecho, todo el concurso, que incluyó la evaluación de los pueblos de todas las principales provincias de norte a sur, de la costa al interior, funcionó implícita pero efectivamente para demarcar a Portugal como un independiente e inviolable Estado nación. Tal como fue llevado a cabo en 1938, el concurso como proceso - la enorme publicidad que durante ocho meses rodeó la visita de cada juri de un pueblo a otro- actuó para reforzar y celebrar la soberanía portuguesa en mucha mayor medida en la que lo hizo la mera declaración de Monsanto como «El pueblo más portugués de Portugal». Después de todo, el Portugal de Salazar fue mucho más que Monsanto.

Como se informó en el Diário de Noticias (24, agosto, 1938), «De norte a sur, en muchos rincones del país la gente vive en un perfecto estado de gracia nacional, sin haber sufrido influencias extranjeras nocivas y manteniendo intactas - como se puede comprobar - la pureza y el encanto, las costumbres tradicionales de la tierra».

Agradecimientos: Deseo hacer constar mi agradecimiento a los investigadores que generosamente me ofrecieron información e ideas que me ayudaron a escribir este artículo: Tiago Castela, Pedro Gabriel Silva, Paula Mota Santos y Francisco Vaz da Silva. La investigación recibió apoyo económico en dos ocasiones distintas del Programa de Estudios Portugueses de la Universidad de California, Berkeley. Funcionarios de la Hemeroteca Municipal de Lisboa dieron amablemente su tiempo mientras yo investigaba en los periódicos y documentos relevantes para la investigación. Una versión previa de este artículo fue presentada en el Annual Meeting of the American Anthropological Association en San Francisco, Noviembre de 2012. Traducción de Sonia Cajade Frias.

\section{Bibliografía}

Alves, V. (1997). Os etnógrafos locais e o Secretariado da Propaganda Nacional: Um estudio de caso. Etnográfica 1 (2):237-257.

Brandes, S. (2011). «El nacimiento de la antropología social en España». En Díaz Viana, L., Fernández Álvarez, O. y Tomé, P., eds., Lugares, tiempos, memorias: la antropología ibérica en el siglo XXI, León: Universidad de León, pp. 27-50.

Galinier, J. (2006). L’anthropologie hors des limites de la simple raison: Actualité de la dispute entre Kant et Herder. L'Homme 179:141-164. 
Nascimento, C. (2011). A Aldeia mais Portuguesa de Portugal: Trabalho de Etnomusicologia. http://natura.di.uminho.pt/ipm.10/doku.php?id=documentacao.

Pais de Brito, J. (1982). «O Estado Novo e a Aldeia Mais Portuguesa de Portugal». En O Fascismo en Portugal: Actas de Coloquio. Lisboa: Avegra do Jogo, pp. 511-532.

Payne, S. (2008). Franco and Hitler: Spain, Germany, and World War II. New Haven: Yale University Press.

Zammito, J. (2002). Kant, Herder, and the Birth of Anthropology, Chicago: University of Chicago Press.

Recibido: $12 / 06 / 2013$

Aceptado: 7/09/2013 